\title{
Development of an indirect ELISA to specifically detect antibodies against African swine fever virus: bioinformatics approaches
}

\author{
Zhan Gao, Jun-Jun Shao, Guang-Lei Zhang, Su-Dan Ge, Yan-Yan Chang, Lei Xiao and Hui-Yun Chang* (i)
}

\begin{abstract}
Background: African swine fever (ASF), characterized by acute, severe, and fast-spreading, is a highly lethal swine infectious disease caused by the African swine fever virus (ASFV), which has caused substantial economic losses to the pig industry worldwide in the past 100 years.

Methods: This study started with bioinformatics methods and verified the epitope fusion protein method's reliability that does not rely on traditional epitope identification. Meanwhile, it will also express and purify the constructed genes through prokaryotic expression and establish antibody detection methods.
\end{abstract}

Results: The results indicated that the protein had good reactivity and did not cross-react with other swine diseases. The receiver-operating characteristic analysis was performed to verify the determination. The area under the receiveroperating characteristic curve was 0.9991 (95\% confidence interval 0.9973 to 1.001).

Conclusions: It was proved that the recombinant protein is feasible as a diagnostic antigen to distinguish ASFV and provides a new idea for ASFV antibody detection.

Keywords: African swine fever virus, Indirect enzyme-linked immunosorbent assay, Recombinant protein, Multiepitope

\section{Introduction}

ASF is an acute, highly contagious swine infection caused by ASFV, with a fatality rate of up to $100 \%$ [1]. It has also resulted in substantial economic losses in the pig industry in affected areas. The World Animal Health Organization (OIE) included ASF in the list of notifiable animal diseases. ASF was first discovered in Kenya, Africa, in 1921. Before 1957, ASF outbreaks occurred only in Africa and subsequently spread to Europe and the Americas; But, except for Sardinia, the outbreak was under control. In

\footnotetext{
*Correspondence: changhuiyun@caas.cn

State Key Laboratory of Veterinary Etiological Biology, OIE/National Foot-and-Mouth Disease Reference Laboratory, Lanzhou Veterinary Research Institute, Chinese Academy of Agricultural Sciences, No. 1 Xujiaping, Yanchangbao, Chengguan District, Lanzhou 730046, Gansu, China
}

2007, ASF was introduced into Georgia and then through Georgia to Armenia, Azerbaijan, Russia, and other countries [2]. Furthermore, in August 2018, it was introduced into China for the first time, where it is a significant animal disease that needs to be prevented and controlled. No commercial vaccines are currently available; Thus, it is of great significance to establish an effective detection method for the prevention and treatment of ASF.

ASFV has a regular hexagonal shape with a diameter of about $200 \mathrm{~nm}$. Plus, the virus particle comprises five parts: the nucleoid, core shell, inner envelope, capsid, and external envelope, from the inside to the outside. It encodes 54 structural proteins and more than 100 nonstructural proteins [3]. In the face of such a complicated virus, traditional immunological test methods are undoubtedly time-consuming and laborious. Bioinformatics is an interdisciplinary field, and computers can original author(s) and the source, provide a link to the Creative Commons licence, and indicate if changes were made. The images or other third party material in this article are included in the article's Creative Commons licence, unless indicated otherwise in a credit line to the material. If material is not included in the article's Creative Commons licence and your intended use is not permitted by statutory regulation or exceeds the permitted use, you will need to obtain permission directly from the copyright holder. To view a copy of this licence, visit http://creativecommons.org/licenses/by/4.0/. The Creative Commons Public Domain Dedication waiver (http://creativeco mmons.org/publicdomain/zero/1.0/) applies to the data made available in this article, unless otherwise stated in a credit line to the data. 
draw rules and insights from the stored large amounts of biological, immunological test data through simulation and analogy. In this way, when the genome or protein sequence information of a new virus is obtained, the computer can analyze the virus's characteristics and the pathogen's critical epitopes based on past "experience". It can significantly reduce blindness in the experiment process.

To study whether the bioinformatics method can be used as a biological tool worthy of our trust, we predict the epitope of ASFV and use specific tests to prove whether it meets the expected effect. As a result, this study tried to predict the P30 and P54 proteins' main epitopes directly and create artificially synthesized genes with a small molecular weight and are easy to express; we named the diagnostic antigen m35. All selected epitopes are conserved sequences in the Chinese strains 2018AnhuiXCGQ, DBLN2018, and PigHLJ2018 and the standard ASF strain Georgia 2007/1. We expressed the fusion gene in the prokaryotic expression system, analyzed the recombinant protein's immune characteristics by Western blot, and then established an indirect enzyme-linked immunosorbent assay (ELISA) method based on the protein, offering an effective way for the timely diagnosis of ASFV.

\section{Materials and methods}

\section{Computer prediction of epitopes}

The sequences of $\mathrm{p} 30$ and p54 proteins of ASFV (GenBank: MK128995.1) were obtained from NCBI (http:// www.ncbi.nlm.nih.gov). B cell epitope is mainly played in viral serum testing, so four online epitope prediction tools DNAStar, ABCpred Prediction (http://crdd.osdd. net/raghava/abcpred/ABC_submission.html), Scratch (http://scratch.proteomics.ics.uci.edu/) and IEDB (http:// www.iedb.org/) were applied to screen the most immunogenic B cell epitopes. Since characterization of the peptide-binding specificity of swine leukocyte antigen (SLA) class I is critical to the adaptive immune response of the porcine infectious disease, it is of great significance to screen the screening of the original epitope. Here, we use NetMHCpan BA 4.1 to predict the binding affinity of peptides in proteins.

\section{Construction and predicted characteristics of multi-epitope $\mathrm{m} 35$ protein}

The epitopes are linked together by the linker "GGGGS" and added to its 3 'end the $6 \times$ His tag, whose codons were optimized for pET-28a (+), was synthesized by Nanjing Genscript. Protein secondary structure was determined using PROTEAN (DNASTAR software) and PSIRED (http://bioinf.cs.ucl.ac.uk/psipred/) [4]. It provides information on connection analysis, folding recognition, structure modeling, function prediction, protein imbalance prediction, and query sequence domain prediction.

\section{Expression and purification of recombinant protein}

The synthetic recombinant plasmid was transformed into E. coli BL21 (Sangon Biotech Co., Ltd Shanghai China). The transformed E. coli BL21 cells were grown by adding a small amount of Luria-Bertani (LB) in a shaker at $220 \mathrm{rpm}$ and $37^{\circ} \mathrm{C}$ and then inoculated into a large bottle of LB (containing $30 \mu \mathrm{g} / \mathrm{ml}$ kanamycin) at a dilution of 1:100. After $3 \mathrm{~h}, 1 \mathrm{mM}$ isopropyl $\beta-\mathrm{d}-1$ thiogalactopyranoside (IPTG) (Solarbio, Beijing, China) was added to induce protein synthesis for $4 \mathrm{~h}$. The bacteria were collected by centrifugation. The pellet was suspended in a binding buffer $(0.5 \mathrm{M} \mathrm{NaCl}, 50 \mathrm{mM}$ Tris, and $5 \mathrm{mM}$ imidazole; $\mathrm{pH}$ 8.0) for sonication. Centrifuge the lysate after sonication and resuspend the pellet (in the form of inclusion bodies) in a binding buffer containing $8 \mathrm{M}$ urea, dissolve and centrifuge at $4{ }^{\circ} \mathrm{C}$ overnight, and purify the His-tag-containing recombinant protein by affinity chromatography using NiSepharose TM excel (GE). The purified protein was refolded in dialysate (0.25 M NaCl, $50 \mathrm{mM}$ Tris, $0.5 \mathrm{Mm}$ EDTA, $2 \mathrm{mM} \mathrm{GSH}$ and $0.2 \mathrm{mM}$ GSSG; pH8.0) at $4{ }^{\circ} \mathrm{C}$, and contained different concentrations of urea (6 $\mathrm{M}$ to $0 \mathrm{M}$ in decreasing order of $1 \mathrm{M})$. Finally, the protein was dialyzed twice in PBS ( $\mathrm{pH}$ 7.4) to obtain a fully refolded protein, and the protein concentration was measured with the BCA protein detection kit (Takara) [5].

\section{SDS-PAGE, western blot analysis}

Separate the same amount of protein using 12\% SDSPAGE electrophoresis. After completion, the gel was stained with Coomassie Blue R250 or transfer to a $0.45 \mu \mathrm{m}$ polyvinylidene fluoride (PVDF: Millipore, USA) membrane for Western blot analysis. The primary antibodies were mouse anti-His monoclonal antibody (mAb; Abcam, MA) and ASFV positive serum.

To put it in a nutshell, the transferred membrane was blocked for $1 \mathrm{~h}$ at $37{ }^{\circ} \mathrm{C}$ in PBST containing 5\% skim milk, and then the membrane was incubated overnight with diluted $\mathrm{mAb}$ or positive serum at $4{ }^{\circ} \mathrm{C}$. The membrane was washed 3 times with PBST and incubated with diluted goat anti-mouse and goat anti-pig conjugated horseradish peroxidase (HRP; Abcam) secondary antibodies at $37^{\circ} \mathrm{C}$ for $1 \mathrm{~h}$. The membrane was washed 3 times with PBST, and a signal was generated using diaminobenzidine (DAB; Solarbio, Beijing, China).

\section{iELISA}

Coated 96-well microtiter plate with gradient concentration recombinant protein (Corning, USA) and placed at 4 degrees Celsius. Incubate overnight. After washing 3 
times with PBST, blocking with 5\% skimmed milk powder at $37{ }^{\circ} \mathrm{C}$ for $2 \mathrm{~h}$, and then washing 3 times, incubated with the positive serum of different dilutions $(100 \mu \mathrm{L}$ per well) at $37{ }^{\circ} \mathrm{C}$ for $1 \mathrm{~h}$, then wash the wells 3 times, and dilute anti-swine IgG antibody to $1: 20,000$, add $100 \mu \mathrm{L}$ per well, incubate for $30 \mathrm{~min}$ at $37{ }^{\circ} \mathrm{C}$. After washing 3 times with PBST, $100 \mu \mathrm{L}$ of TMB substrate was added to each well. After reacting at $37^{\circ} \mathrm{C}$ for $15 \mathrm{~min}, 100 \mu \mathrm{L}$ per well of stop solution $\left(2 \mathrm{M} \mathrm{H}_{2} \mathrm{SO}_{4}\right)$ was added. All samples were simultaneously measured OD at $450 \mathrm{~nm}$ using an ELISA microplate reader (BioTek, USA). And set up positive and negative controls.

After establishing the optimal coating concentration and dilution concentration, we tested 56 negative serum samples to determine the Cut-off value.

$$
\text { Cut-off }=\overline{\mathrm{X}}+3 \mathrm{SD}
$$

Dot plot and receiver-operating characteristic (ROC) were performed while using the GraphPad Prism version 7.0 for Windows.

293 serum samples from Professional laboratory in Lanzhou Veterinary Research Institute, Chinese Academy of Agricultural Sciences, Lanzhou, Gansu, China:

(1) 215 serum samples of negative controls were obtained from pig farms in 2015.

(2) 78serum samples of ASFV positive were obtained from the Regional Laboratory of ASF, Lanzhou Veterinary Research Institute. Positive samples include 9 ASF carrier pigs that had recovered entirely from acute infection with ASFV.

\section{Cross-reaction experiment of ELISA}

To validate the cross-reactivity, this m 35 indirect ELISA was utilized to test porcine serum positive for other swine pathogens, including pseudorabies virus (PRV), porcine reproductive and respiratory syndrome virus (PRRSV), porcine circovirus (PCV), porcine epidemic diarrhea virus (PEDV), porcine delta coronavirus (PDCoV), classical swine fever virus (CSFV), and foot-and-mouth disease virus (FMDV). The positive sera were kept in our laboratory, State Key Laboratory of Veterinary Etiological Biology, Lanzhou Veterinary Research Institute. Each sample was repeated in triplicate.

\section{Identification of B cell epitopes}

We used the ELISA method to detect the reactivity of each epitope in the recombinant protein. The polypeptide composed of the recombinant protein and other predicted dominant epitopes was sent to GenScript for synthesis. The synthesized polypeptide was used as the coating antigen to identify the epitope by positive serum
Initial identification. The steps are completed following the instructions of the Takara Peptide Coating Kit.

\section{Result}

\section{Construction of multiple epitope genes}

The Chinese strain 2018/AnhuiXCGQ genome's genebank is MK128995.1. The results of using ABCpred Prediction, Scratch, and IEDB are shown in Table 1. According to the number of protein sequences in different threshold stages in the method, we set the Scratch threshold to 0.78, ABCpred Prediction to 0.87, and the threshold of IEDB to 0.500 . The analysis results of SLA-1 are shown in Table 2, and the selected allele type is SLA-1 * 0401, which is one of the most frequently found alleles in different kinds of pigs [6]. We choose 9mers peptides with potential binding SLA-1*0401 [7], and all selected peptides had a NetMHCpan rank score of $<2 \%$ [8]. Remove non-conservative sequences such as 153-158 in P30 by BLAST. The epitope we finally selected was repeated more, a high score in three prediction methods, and better peptide-SLA-1 binding ability in the NetMHCpan peptide prediction algorithm, as shown in Table 3.

\section{Predicted characteristics of $\mathrm{m} 35$ protein}

To avoid the emergence of new epitopes, the authors added the "GGGGS"linker in the middle of each epitope (Fig. 1). Through the Protean program (Fig. 2) to predict the antigenic index, hydrophobicity, and surface probability, it can be observed that the protein has a certain degree of hydrophilicity and a high antigenic index. Predictive analysis of secondary structure by PSIRED shows the presence of four alpha helices $(\alpha 1,2-14 ; \alpha 2,56-72$;

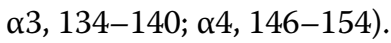

\section{Recombinant protein expression, purification and identification}

A synthetic 558-bp gene was synthesized by optimizing E. coli expression codons by Nanjing GenScript. Then the gene sequence was inserted into the bacterial expression vector pET-28a and transformed into E. coli BL21 (DE3) cells (Fig. 3). After induction, sonication, and analysis by SDS-PAGE, it can be seen that the recombinant protein is expressed. Select Ni-NTA affinity purification to obtain the purified product. Eventually, the authors obtained $1 \mathrm{ml}$ of $\mathrm{m} 35$ protein solution with a concentration of $1.4 \mathrm{mg} / \mathrm{ml}$. The immunoreactivity of $\mathrm{m} 35$ protein was checked by Western blot. We can see that the recombinant protein can react with HIS monoclonal antibody and ASFV positive serum, respectively.

\section{iELISA}

The results of the checkerboard titration method are shown in Table 4.When the positive serum OD value is 
Table 1 Prediction of B cell epitope of ASFV structural protein p30 and p54

\begin{tabular}{|c|c|c|c|c|c|c|c|c|c|}
\hline \multirow[t]{2}{*}{ Protein } & \multicolumn{3}{|l|}{ Scratch } & \multicolumn{3}{|c|}{$A B C p r e d$ prediction } & \multicolumn{3}{|l|}{ IEDB } \\
\hline & Start position & Sequence & Score & Start position & End position & Score & Start position & End position & NO \\
\hline \multirow[t]{14}{*}{ p30 } & 173 & PLKEEE & 0.92724943 & 155 & 174 & 0.93 & 15 & 24 & 1 \\
\hline & 172 & TPLKEE & 0.88402353 & & & & & & \\
\hline & 153 & APDFNK & 0.88343295 & 65 & 80 & 0.90 & 31 & 35 & 2 \\
\hline & 72 & GYTEHQ & 0.88222533 & & & & & & \\
\hline & 173 & PLKEEEK & 0.87789045 & 140 & 153 & 0.89 & 63 & 84 & 3 \\
\hline & 172 & TPLKEEE & 0.84681755 & & & & & & \\
\hline & 115 & TSSFET & 0.81093245 & 175 & 194 & 0.88 & 92 & 117 & 4 \\
\hline & 114 & CTSSFE & 0.80846832 & & & & & & \\
\hline & 113 & ECTSSF & 0.80761785 & 146 & 165 & 0.87 & 120 & 136 & 5 \\
\hline & 73 & YTEHQAQ & 0.79960905 & & & & & & \\
\hline & 114 & CTSSFET & 0.79736268 & 75 & 92 & 0.87 & 145 & 162 & 6 \\
\hline & 19 & RSSSQV & 0.78848895 & & & & & & \\
\hline & 71 & QGYTEH & 0.7840783 & 134 & 151 & 0.87 & 164 & 181 & 7 \\
\hline & 73 & YTEHQA & 0.78333067 & & & & & & \\
\hline \multirow[t]{9}{*}{ P54 } & 173 & TYTHKD & 0.91484526 & 157 & 174 & 0.93 & 5 & 24 & 1 \\
\hline & 145 & PAEPYT & 0.83470635 & 48 & 61 & 0.90 & & & \\
\hline & 144 & HPAEPYT & 0.81938788 & 128 & 147 & 0.88 & & & \\
\hline & 173 & TYTHKDL & 0.81866632 & 5 & 20 & 0.88 & 54 & 122 & 2 \\
\hline & 155 & QNTASQ & 0.81150261 & 2 & 13 & 0.87 & & & \\
\hline & 174 & YTHKDLE & 0.80539209 & 76 & 89 & 0.87 & & & \\
\hline & 146 & AEPYTT & 0.79759747 & 65 & 78 & 0.87 & 132 & 180 & 3 \\
\hline & 172 & NTYTHK & 0.79226505 & 159 & 174 & 0.87 & & & \\
\hline & 174 & YTHKDL & 0.78092143 & 140 & 155 & 0.87 & & & \\
\hline
\end{tabular}

Scratch, ABCpred prediction: the higher the score, the more likely the epitope, the IEDB orders the epitope from most likely to least likely

Table 2 Peptide candidates for SLA-1*0401 affinity analysis (low consensus score $=$ good binder)

\begin{tabular}{ccll}
\hline Protein & Start-end position & Sequence & $\begin{array}{l}\text { NetMHCpan } \\
\text { predicted\% rank } \\
\text { score }\end{array}$ \\
\hline p30 & $25-33$ & VVFHAGSLY & 0.13 \\
& $111-119$ & ETNECTSSF & 0.2 \\
$143-151$ & KTVQHIEQY & 0.23 \\
$52-60$ & KTLLSTVKY & 0.24 \\
$115-123$ & CTSSFETLF & 0.29 \\
$79-87$ & AQEEWNMIL & 1.4 \\
$7-15$ & ISMKMEVIF & 1.7 \\
$61-69$ & AIEEEDIQF & 0.19 \\
$2-10$ & DSEFFQPVY & 0.94 \\
p54 & LSPVTTPSF & 1.3 \\
& $73-81$ & YQDQQWVEV & 1.3 \\
$142-150$ & APAHPAEPY & 1.5 \\
$155-163$ & TQNTASQTM & 1.5 \\
$161-169$ & QTMSAIENL & 1.7 \\
\hline
\end{tabular}

Table 3 B cell epitope sequences selected in p30 and p54

\begin{tabular}{lll}
\hline Protein & Start-end position & Sequence \\
\hline p30 & $15-28$ & FKTDLRSSSQVVFH \\
& $24-33$ & QVVFHAGSLY \\
& $73-80$ & GYTEHQAQ \\
& $115-123$ & CTSSFETLF \\
& $173-181$ & TPLKEEEKE \\
& $182-193$ & WVRLMVIKLLKK \\
& $17-26$ & CLSPVTTPSF \\
P54 & $145-161$ & HPAEPYTTVTTQNTASQ \\
& $160-169$ & SQTMSAIENL \\
& $167-181$ & ENLRQRNTYTHKDLE \\
\hline
\end{tabular}

The epitope with a good score and more conservatism was finally selected through four prediction methods

around 1 and the $\mathrm{P} / \mathrm{N}$ value is relatively large, the conditions are optimal (shown in the red wire frame).so we choose the best coating concentration to be $0.25 \mu \mathrm{g} / \mathrm{mL}$, the best serum dilution concentration is $1: 100$, and the determination results of 56 negative sera are shown in Table 5, calculated by the formula cut-off value is 0.3380 . 


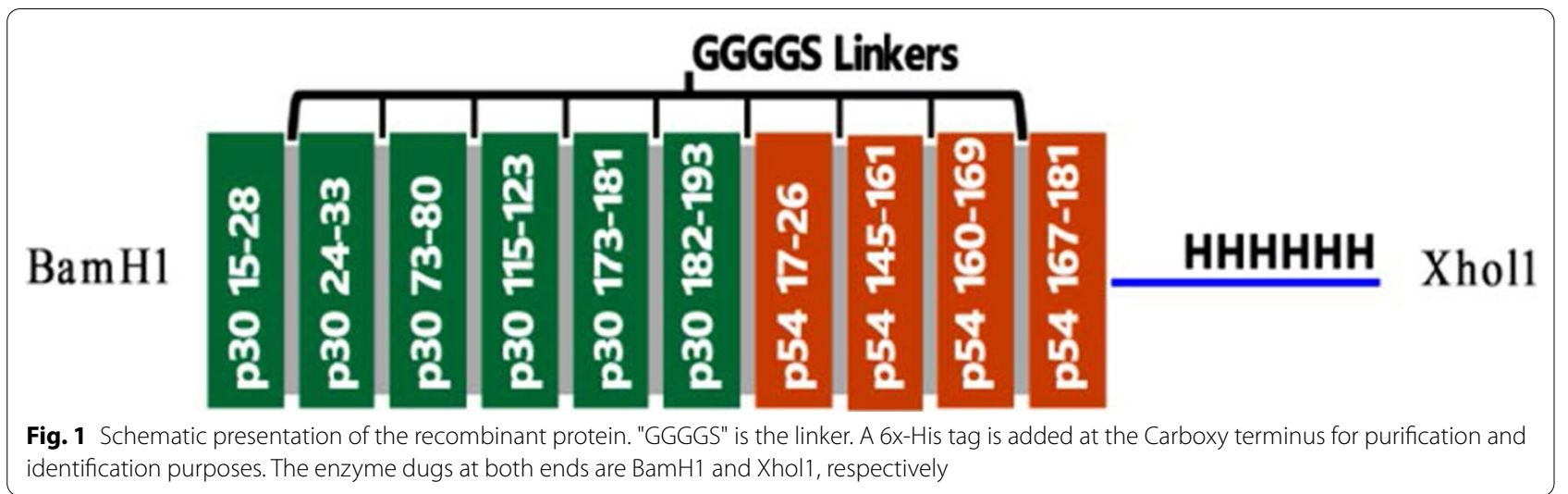

a

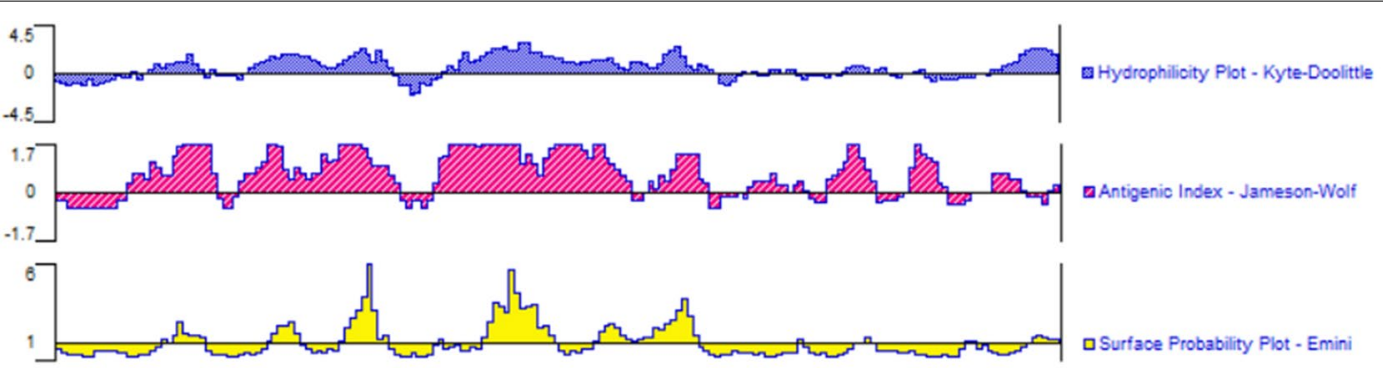

b

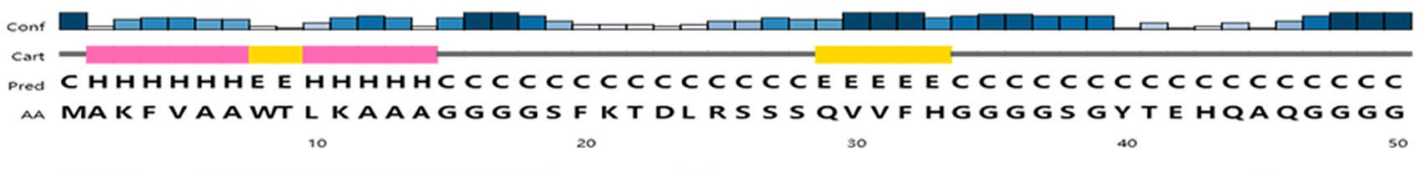

Cart

PA STPLKEEEKEVVRL MVIKLLKKGGGGSENLRQRNTYTHKDLEGGGGSHPA

70

90

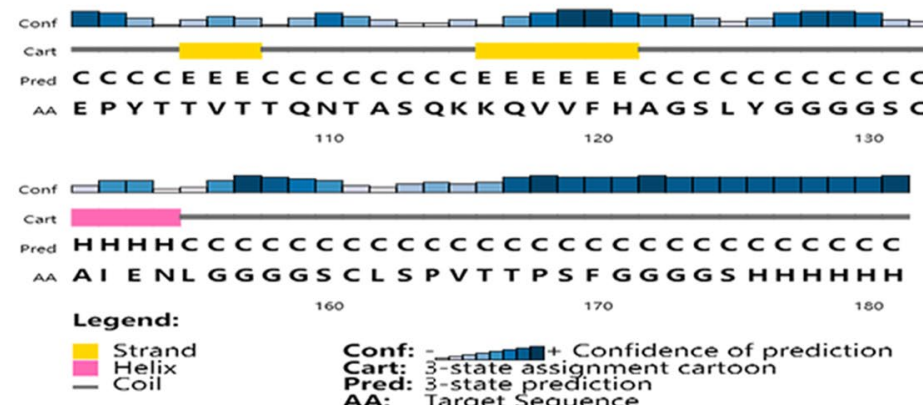

ताम

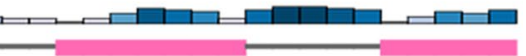

CHHHHHHHCCCCCHHHHH SSFETLFGGGGSSOTMS

AA: Target Sequence

Fig. 2 Bioinformatics prediction analysis of m35 protein. a Protean predicted the physical and chemical properties of proteins. b PSIPRED was used to predict the secondary structure of the protein

To assess the method's sensitivity, 293 serum samples were tested by indirect ELISA, including positive serum (78 samples) and negative serum (215 samples). The dot plot summarizes the OD values of these samples (Fig. 4).
ROC analysis was performed to assess the best sensitivity and specificity. The AUC for this test was 0.9991 ( $95 \%$ confidence interval (CI) 0.9973to 1.001) based on ROC analysis. Also, the diagnostic sensitivity of $98.72 \%$ (95\% 
a

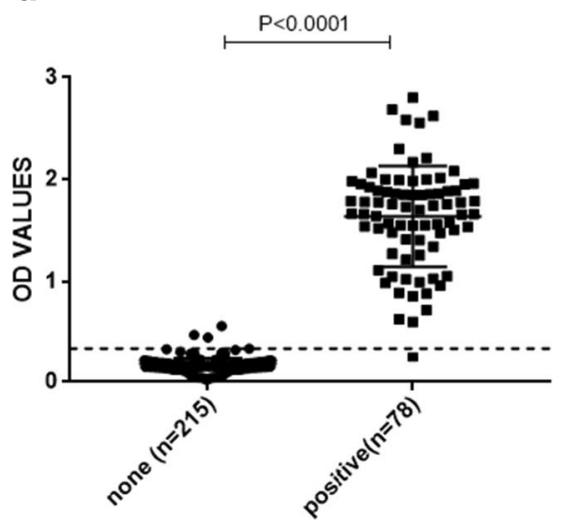

b

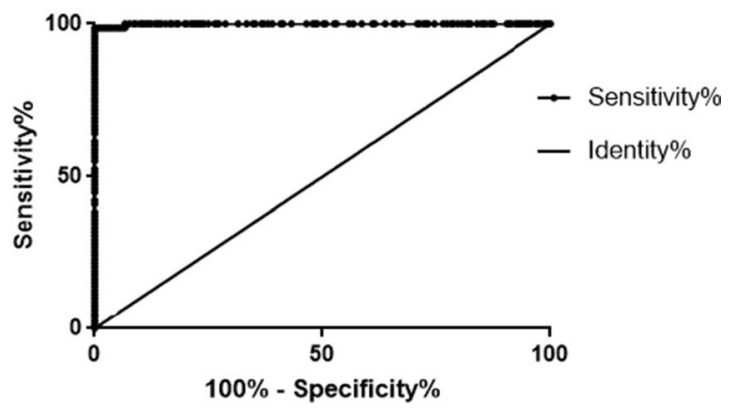

Fig. 3 Preparation of recombinant protein. SDS-PAGE analysis of m35 protein a (M, marker; Lane 1, uninduced cells; Lane 2, IPTG-induced cells for 4 h) b (M, marker; Lane 3, the supernatant of IPTG-induced cells; Lane 4, deposition of IPTG-induced cells) c (M, marker; Lane 5, purified recombinant protein) Western blotting analysis of the purified recombinant protein using the mouse anti-His monoclonal antibody (mAb) (d) and the ASFV-positive serum (e)
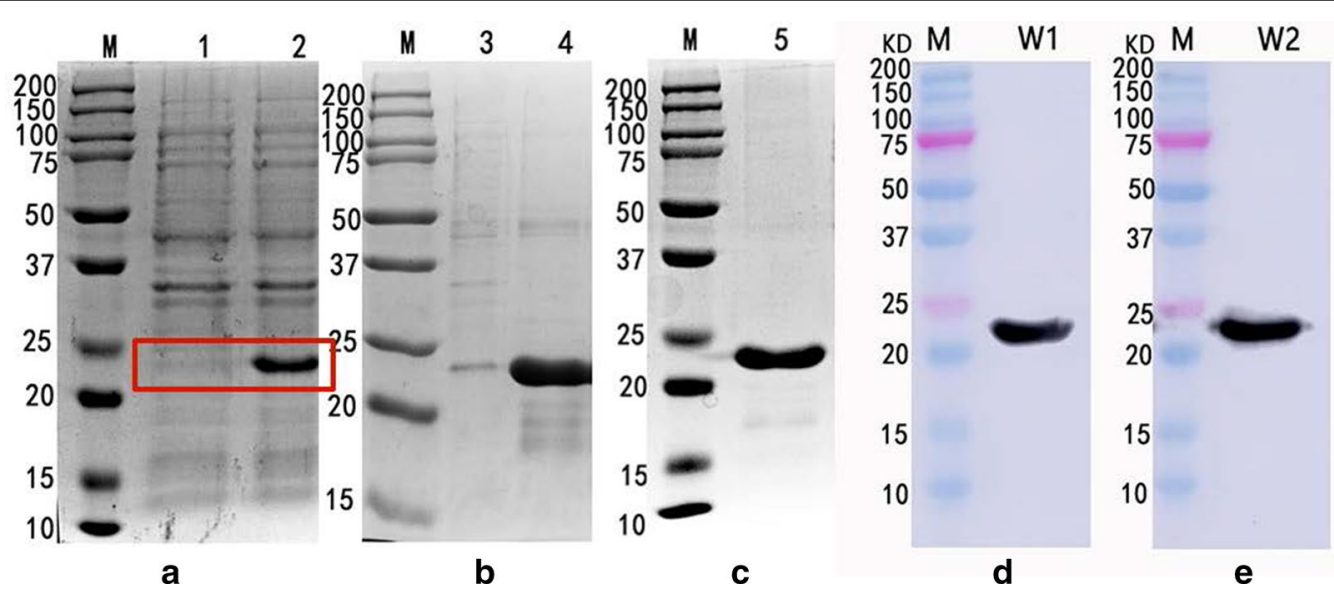

Fig. 4 IELISA analysis of serum samples. a Dot plot of the m35 iELISA assay. $\mathbf{b}$ ROC analysis of m35 iELISA assay results. The results of the ELISA confirming $98.72 \%$ sensitivity and $98.14 \%$ specificity

CI, 93.06 to 99.97$)$ and a specificity of $98.14 \%(95 \% \mathrm{CI}$, 95.31 to 99.49$)$ were attained from the optimal cut-off value (0.3380).

It is worth mentioning that under the cut-off value of 0.3380 , all ASF carrier pig samples are positive.

\section{Cross-reaction experiment of ELISA}

Evaluating the specificity and sensitivity of ELISA Crossreaction test was performed on PRV, PRRSV, PCV, PDCoV, CSFV, and FMDV positive sera using established ELISA methods. The results demonstrated that these serum samples were ASFV-seronegative and non-crossreactive with this $\mathrm{m} 35$ indirect ELISA (Fig. 5), indicating that the established ELISA was an effective method for detecting ASFV antibodies.

\section{B cell epitope identification results}

The kit was used to detect the dominant B cell epitope in the recombinant protein. The results are shown in Fig. 6 . The p54 protein sequence 145-151 (HPAEPYTTVT) has a significantly higher reactivity with the African swine fever virus positive serum than other peptides.

\section{Discussion}

The current laboratory diagnostic procedures for ASF include animal vaccination, virus isolation, virus nucleic acid testing, and specific antibody testing. Of these, animal vaccination, virus isolation, and viral nucleic acid detection require professionals who work in laboratories above level 3 [9]. Despite that objective data are obtained, the cumbersome operation limits its wide 
Table 4 Checkerboard titration results

\begin{tabular}{ccccccc}
\hline \multirow{2}{*}{ Serum dilution } & & \multicolumn{5}{c}{ Protein coating concentration $(\mu \mathrm{g} / \mathrm{mL})$} \\
& $\mathrm{P} / \mathrm{N}$ & 1 & 0.5 & 0.25 & 0.125 & 0.0625 \\
\hline \multirow{2}{*}{$1: 50$} & $\mathrm{P}$ & 3.734 & 2.606 & 1.236 & 0.405 & 0.265 \\
& $\mathrm{~N}$ & 0.440 & 0.425 & 0.431 & 0.326 & 0.304 \\
& $\mathrm{P}$ & 3.539 & 2.497 & 1.013 & 0.420 & 0.219 \\
$1: 100$ & $\mathrm{~N}$ & 0.228 & 0.248 & 0.201 & 0.192 & 0.182 \\
& $\mathrm{P}$ & 2.951 & 2.057 & 0.850 & 0.352 & 0.205 \\
$1: 200$ & $\mathrm{~N}$ & 0.133 & 0.142 & 0.145 & 0.128 & 0.119 \\
& $\mathrm{P}$ & 2.063 & 1.559 & 0.815 & 0.296 & 0.182 \\
$1: 400$ & $\mathrm{~N}$ & 0.094 & 0.093 & 0.098 & 0.083 & 0.082 \\
\hline
\end{tabular}

P: positive serum; $\mathrm{N}$ : negative serum. Condition select the maximum P/N value, and the P-value is about 1 from the protein coating concentration and serum dilution such as the red frame chosen

Table 5 ASFV negative serum sample test result

\begin{tabular}{|c|c|c|c|c|c|c|c|}
\hline \multicolumn{8}{|c|}{ Negative serum $\mathrm{OD}_{450 / 630 \mathrm{~nm}}$} \\
\hline 0.170 & 0.210 & 0.170 & 0.23 & 0.214 & 0.177 & 0.181 & 0.221 \\
\hline 0.165 & 0.238 & 0.238 & 0.222 & 0.150 & 0.158 & 0.340 & 0.336 \\
\hline 0.121 & 0.220 & 0.080 & 0.160 & 0.218 & 0.198 & 0.231 & 0.248 \\
\hline 0.220 & 0.181 & 0.181 & 0.186 & 0.221 & 0.236 & 0.179 & 0.192 \\
\hline 0.213 & 0.162 & 0.162 & 0.217 & 0.298 & 0.186 & 0.236 & 0.216 \\
\hline 0.170 & 0.140 & 0.140 & 0.228 & 0.231 & 0.133 & 0.236 & 0.179 \\
\hline 0.175 & 0.161 & 0.161 & 0.203 & 0.208 & 0.166 & 0.228 & 0.151 \\
\hline
\end{tabular}

application, cumbersome operation limits its widespread applications. Although polymerase chain reaction (PCR), Loop-mediated isothermal amplification (LAMP), and recombinase polymerase amplification (RPA) are simple, sensitive, and responsible. Still, it may carry over contaminants in fields and cause false positives [10-14]. Due to its simple procedure and low cost, serological testing is a commonly used diagnostic method for ASFV [15]. It is one of the most important methods for diagnosing and monitoring pigs infected with ASFV [16].

It is not uncommon to use bioinformatics technology to develop vaccines. The tertiary structure of a protein is affected by the secondary structure, and the secondary structure of a protein often affects its potential as an epitope. For example, the $\alpha$-helix and $\beta$-sheet structures of proteins are relatively stable, not suitable for deformation, and it is difficult for chimeric antibodies to become epitopes. However, $\beta$-turns and random coils are more likely to protrude on the protein's surface, which is relatively loose and easily twisted., It is easier to become the dominant epitope of B cells. AREGA et al. [17] applied bioinformatics and immunoinformatics methods to computer docking and molecular dynamics simulation of tuberculosis receptors to screen out candidate subunit vaccines that can cause tuberculosis-specific cellular and humoral immune responses. MULPURU et al. [18] identified CTL epitopes of COVID-19 based on immunoinformatics and used sequence conservation studies and molecular dynamics models to identify the epitopes further. SADAT et al. [19] compared and analyzed the protein sequence's structural characteristics and immunogenicity in COVID-19, established a model, and evaluated the MHC-I and MHC-II epitopes with higher antigenicity. 


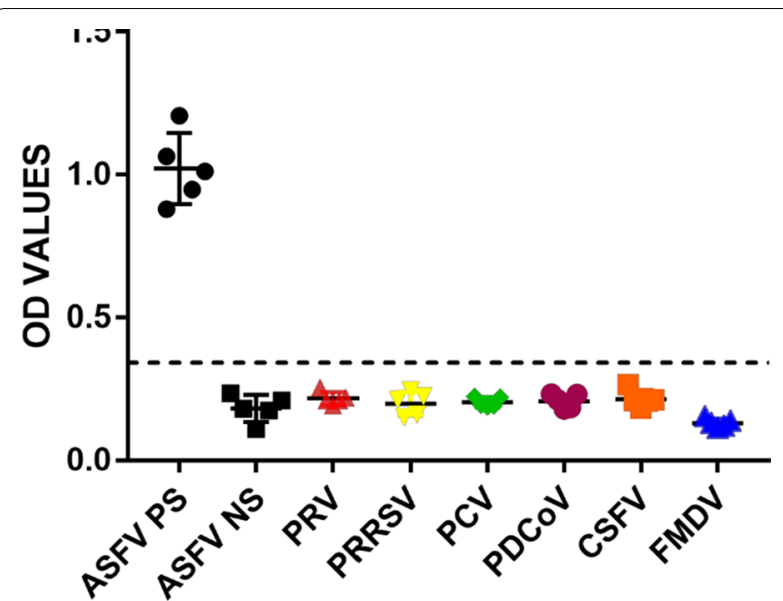

Fig. 5 IELISA analysis of other swine disease serum samples. ASFV PS: ASFV positive serum, NS: negative serum, Using PRV, PRRSV, PCV, PDCoV, CSFV, FMDV positive serum test ELISA reaction, OD value is lower than the cut-off value

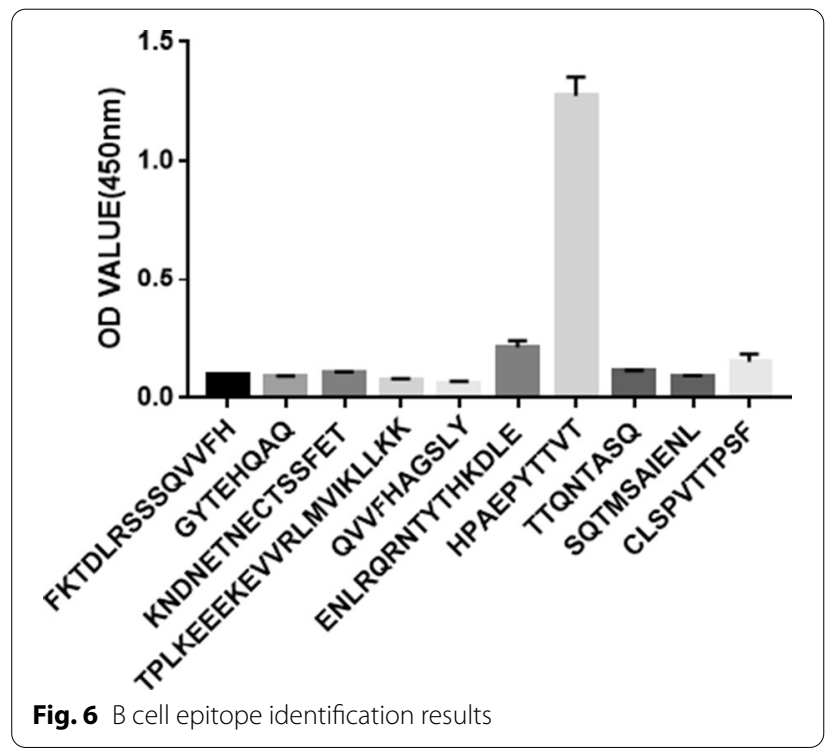

Here we chose P30 and P54 proteins as the target of epitope prediction. Although P30 and P54 have been applied in detecting ASFV antibodies as early as in the last century [20], both P30 and P54 can induce specific immune responses [21]. P30 protein, encoded by CP204L, mainly involves virus internalization and plays an essential role in virus entry into the host cell [22]. Additionally, P30 protein levels are higher in the early stages of viral infection and induce neutralizing antibodies [23]. The P54 protein encoded by the E183L gene is present in the inner envelope of virions and is involved in the virus's adsorption and entry. Therefore, the P30 and P54 proteins are ideal antigens for serological diagnosis and immunological detection [24, 25]. We linked the prediction results to a recombinant protein to test it as a diagnostic antigen. From the two prediction methods in Fig. 2, it can be seen that the recombinant protein has a larger area of antigenicity. The tested recombinant protein had a small molecular weight, was easy to express, and had a lower production cost. After that, we use the checkerboard titration method to determine the best conditions for establishing ELISA and determine the cut-off value by measuring negative serum samples. Then serum samples with a transparent background were used for ROC analysis. The initial results revealed that the antigen had high sensitivity and specificity $(0.9<\mathrm{AUC}<1)$. After testing, no reaction was noted in the case of other pig diseases. Consequently, it is feasible to use the $\mathrm{m} 35$ recombinant protein as a diagnostic antigen to distinguish ASFV infection.

Besides, recent studies have shown that clinically healthy ASFV infection survivors who become carriers can transmit ASFV to pigs on contact [26]. The results of the iELISA method were positive while using survivors' serum samples. Therefore, our method can also play a role in monitoring ASF purification in farms. However, a limitation is that we did not use field serum samples to prove this method's accuracy further. It is worth mentioning that the epitope identified in this study (Fig. 6) P54 protein $145-151$ is consistent with the epitope antigen identified in previous reports [27]. However, ELISA identification results by only positive serum and epitope peptides are still a bit weak because some protein sequences in the virus particles cannot be fully exposed due to conformation and other factors, so that the epitope cannot recognize the positive serum. Amino acids 73-81 and 115-123 in the predicted P30 epitope were approximately the same as those in epitopes 61-90 and $116-125$, as proven in previous reports. Besides, by comparing the previous report, we can see that in the prediction result of the P30 protein epitope, The prediction results of Scratch and IEDB have covered the epitope reported 116-130 and 146-160. In the P54, Scratch and ABCpred Prediction covers this paper and previously reported advantageous antigenic epitopes. And we can also find the importance of predicting the peptide-SLA-1 binding ability, as NetMHCpan's predictions contain almost all previously declared epitope areas [28, 29].

\section{Conclusion}

In conclusion, we use bioinformatics methods to directly predict and analyze the virus structural protein's amino acid sequence and establish an antibody detection method. Compared with the intact protein's ELISA method, the gene sequence of the epitope series owns a small molecular weight and is easier to express. 
Compared with the ELISA method established by traditional epitope proteins, the sequence predicted by bioinformatics saves the time and effort of epitope identification.

\begin{abstract}
Abbreviations
ASF: African swine fever; ASFV: African swine fever virus; Cl: Confidence interval; ELISA: Enzyme-linked immunosorbent assay; LB: Luria-Bertani; PVDF: Polyvinylidene fluoride; HRP: Horseradish peroxidase; DAB: Diaminobenzidine; ROC: Receiver-operating characteristic; PRV: Pseudorabies virus; PRRSV: Porcine reproductive and respiratory syndrome virus; $\mathrm{PCV}$ : Porcine circovirus; PEDV: Porcine epidemic diarrhea virus; PDCoV: Porcine deltacoronavirus; CSFV: Classical swine fever virus; FMDV: Foot-and-mouth disease virus; PCR: Polymerase chain reaction; LAMP: Loop-mediated isothermal amplification; RPA: Recombinase polymerase amplification.
\end{abstract}

\section{Acknowledgements}

All authors would like to thank Guangqing Zhou (Lanzhou Veterinary Research Institute) for helpful discussions.

\section{Authors' contributions}

$\mathrm{GZ}, \mathrm{CH}$ conceived the experiments. GZ, GS, XL performed the experiments. GZ and CY statistically analyzed the data. GZ, SJ, and ZG wrote the manuscript. Funding from $\mathrm{CH}$. All authors read and approved the final manuscript.

\section{Funding}

LVRI Enterprise Cooperation LSY-2018-138.

\section{Availability of data and materials}

Not applicable.

\section{Declarations}

Ethics approval and consent to participate

Not applicable.

\section{Consent for publication}

Not applicable.

\section{Competing interests}

The authors declare no competing interests.

Received: 22 December 2020 Accepted: 29 April 2021

Published online: 05 May 2021

\section{References}

1. Galindo I, Alonso CJV. African swine fever virus: a review. 2017:9:103.

2. Gogin A, Gerasimov V, Malogolovkin A, Kolbasov DJVr. African swine fever in the North Caucasus region and the Russian Federation in years 2007-2012. 2013;173:198-203.

3. Alejo A, Matamoros T, Guerra M, Andres G. A proteomic atlas of the African swine fever virus particle. J Virol. 2018;92:e01293-18.

4. Jones DT. Protein secondary structure prediction based on positionspecific scoring matrices. J Mol Biol. 1999;292:195-202.

5. Ji S, Luo Y, Zhang T, Shao L, Meng XY, Wang Y, Gao Y, Li Y, Li S, Sun Y, Jin $X$, Qiu HJ. An improved indirect ELISA for specific detection of antibodies against classical swine fever virus based on structurally designed E2 protein expressed in suspension mammalian cells. Arch Virol. 2018;163:1831-9.

6. Smith DM, Lunney JK, Martens GW, Ando A, Lee JH, Ho CS, Schook L, Renard C, Chardon P. Nomenclature for factors of the SLA class-I system, 2004. Tissue Antigens. 2005;65:136-49.

7. Nielsen M, Lundegaard C, Blicher T, Lamberth K, Harndahl M, Justesen S, Røder G, Peters B, Sette A, Lund O, Buus S. NetMHCpan, a method for quantitative predictions of peptide binding to any HLA-A and -B locus protein of known sequence. PLOS ONE. 2007;2:e796-e796.

8. Erup Larsen M, Kloverpris H, Stryhn A, Koofhethile CK, Sims S, Ndung'u T, Goulder P, Buus S, Nielsen M. . HLArestrictor-a tool for patient-specific predictions of HLA restriction elements and optimal epitopes within peptides. Immunogenetics. 2011;63:43-55.

9. Oura CAL, Edwards L, Batten CA. Virological diagnosis of African swine fever-Comparative study of available tests. Virus Res. 2013;173:150-8.

10. Yu LS, Chou SY, Wu HY, Chen YC, Chen YH. Rapid and semi-quantitative colorimetric loop-mediated isothermal amplification detection of ASFV via HSV color model transformation. J Microbiol Immunol Infect. 2020. https://doi.org/10.1016/j.jmii.2020.08.003.

11. Miao F, Zhang J, Li N, Chen T, Wang L, Zhang F, Mi L, Zhang J, Wang S, Wang Y, Zhou X, Zhang Y, Li M, Zhang S, Hu R. Rapid and sensitive recombinase polymerase amplification combined with lateral flow strip for detecting African swine fever virus. Front Microbiol. 2019;10:1004-1004.

12. Wang D, Yu J, Wang Y, Zhang M, Li P, Liu M, Liu Y. Development of a real-time loop-mediated isothermal amplification (LAMP) assay and visual LAMP assay for detection of African swine fever virus (ASFV). J Virol Methods. 2020:276:113775.

13. Liu H, Shi K, Sun W, Zhao J, Yin Y, Si H, Qu S, Lu W. Development a multiplex RT-PCR assay for simultaneous detection of African swine fever virus, classical swine fever virus and atypical porcine pestivirus. J Virol Methods. 2020;287:114006.

14. Woźniakowski G, Frączyk M, Kowalczyk A, Pomorska-Mól M, Niemczuk K, Pejsak Z. Polymerase cross-linking spiral reaction (PCLSR) for detection of African swine fever virus (ASFV) in pigs and wild boars. Sci Rep. 2017;7:42903.

15. Cubillos C, Gómez-Sebastian S, Moreno N, Nuñez MC, Mulumba-Mfumu LK, Quembo CJ, Heath L, Etter EM, Jori F, Escribano JM. African swine fever virus serodiagnosis: a general review with a focus on the analyses of African serum samples. Virus Res. 2013;173:159-67.

16. Gallardo C, Soler A, Nieto R, Carrascosa AL, De Mia GM, Bishop RP, Martins C, Fasina FO, Couacy-Hymman E, Heath L, Pelayo V, Martín E, Simón A, Martín R, Okurut AR, Lekolol I, Okoth E, Arias M. Comparative evaluation of novel African swine fever virus (ASF) antibody detection techniques derived from specific ASF viral genotypes with the OIE internationally prescribed serological tests. Vet Microbiol. 2013;162:32-43.

17. Arega AM, Pattanaik KP, Nayak S, Mahapatra RK. Computational discovery and ex-vivo validation study of novel antigenic vaccine candidates against tuberculosis. Acta Trop. 2021. https://doi.org/10.1016/j.actat ropica.2021.105870:105870.

18. Mulpuru V, Mishra N. Immunoinformatic based identification of cytotoxic T lymphocyte epitopes from the Indian isolate of SARS-CoV-2. Sci Rep. 2021;11:4516

19. Sadat SM, Aghadadeghi MR, Yousefi M, Khodaei A, Sadat Larijani M, Bahramali G. Bioinformatics analysis of SARS-CoV-2 to approach an effective vaccine candidate against COVID-19. Mol Biotechnol. 2021. https://doi. org/10.1007/s12033-021-00303-0:1-21.

20. Oviedo JM, Rodríguez F, Gómez-Puertas P, Brun A, Gómez N, Alonso C, Escribano JM. High level expression of the major antigenic African swine fever virus proteins p54 and p30 in baculovirus and their potential use as diagnostic reagents. J Virol Methods. 1997:64:27-35.

21. Chen C, Hua D, Shi J, Tan Z, Zhu M, Tan K, Zhang L, Huang J. Porcine immunoglobulin Fc fused P30/P54 protein of African swine fever virus displaying on surface of $\mathrm{S}$. cerevisiae elicit strong antibody production in swine. Virol Sin. 2020. https://doi.org/10.1007/s12250-020-00278-3.

22. Gómez-Puertas P, Rodríguez F, Oviedo JM, Ramiro-Ibáñez F, Ruiz-GonzaIvo F, Alonso C, Escribano JM. Neutralizing antibodies to different proteins of African swine fever virus inhibit both virus attachment and internalization. J Virol. 1996;70:5689-94.

23. Afonso CL, Alcaraz C, Brun A, Sussman MD, Onisk DV, Escribano JM, Rock $\mathrm{DL}$. Characterization of P30, a highly antigenic membrane and secreted protein of African Swine Fever Virus. Virology. 1992;189:368-73.

24. Gomez-Puertas P, Rodriguez F, Oviedo JM, Ramiro-Ibanez F, Ruiz-GonzaIvo F, Alonso C, Escribano JM. Neutralizing antibodies to different proteins of African swine fever virus inhibit both virus attachment and internalization. JVirol. 1996;70:5689-94.

25. Oviedo JM, Rodriguez F, Gómez-Puertas P, Brun A, Gómez N, Alonso C, Escribano JM. High level expression of the major antigenic African swine 
fever virus proteins p54 and p30 in baculovirus and their potential use as diagnostic reagents. JVirol Methods. 1997;64:27-35.

26. Eblé PL, Hagenaars TJ, Weesendorp E, Quak S, Moonen-Leusen HW, Loeffen WLA. Transmission of African Swine Fever Virus via carrier (survivor) pigs does occur. Vet Microbiol. 2019;237:108345.

27. Petrovan V, Murgia MV, Wu P, Lowe AD, Jia W, Rowland RRR. Epitope mapping of African swine fever virus (ASFV) structural protein, p54. Virus Res. 2020;279:197871.

28. Wu P, Lowe AD, Rodríguez YY, Murgia MV, Dodd KA, Rowland RR, Jia W. Antigenic regions of African swine fever virus phosphoprotein P30 Transbound Emerg Dis. 2020. https://doi.org/10.1111/tbed.13533.
29. Murgia MV, Mogler M, Certoma A, Green D, Monaghan P, Williams DT, Rowland RRR, Gaudreault NN. Evaluation of an African swine fever (ASF) vaccine strategy incorporating priming with an alphavirus-expressed antigen followed by boosting with attenuated ASF virus. Arch Virol. 2019;164:359-70.

\section{Publisher's Note}

Springer Nature remains neutral with regard to jurisdictional claims in published maps and institutional affiliations.
Ready to submit your research? Choose BMC and benefit from:

- fast, convenient online submission

- thorough peer review by experienced researchers in your field

- rapid publication on acceptance

- support for research data, including large and complex data types

- gold Open Access which fosters wider collaboration and increased citations

- maximum visibility for your research: over $100 \mathrm{M}$ website views per year

At BMC, research is always in progress.

Learn more biomedcentral.com/submissions 